\title{
The Human Factor: Unexpected Benefits of a CPOE and Electronic Medication Management Implementation at the University Health Network
}

$\overline{\text { Howard Abrams and Dafna Carr }}$

\section{INTRODUCTION}

For the most part, literature and research around the benefits of computerized physician order entry (CPOE) and electronic medication management (EMM) have focused on the reduction of adverse events and medication errors. While these are major anticipated benefits relating to patient safety, the University Health Network (UHN) discovered that there are other unexpected benefits to be gained, related to human factors, from implementing CPOE and EMM. And they, too, can improve patient safety.

\section{DEFINITION OF EMM}

Throughout this article, EMM is the term used to describe the entire electronic medication process from the physician's order, to the pharmacist's review of the medication, to the nurse's documentation of medication administration and all the processes in between. Figures 1 and 2 describe the medication management workflow pre- and post-implementation of $\mathrm{CPOE}$ and EMM at UHN.

\section{UHN'S IMPLEMENTATION OF CPOE AND EMM}

UHN has been working on implementing electronic medication management (EMM) for a number of years. In its first phase, the project was primarily a technical endeavour, involving two vendors working to interface their products - in UHN's case, the hospital information system (HIS) where the medication order is placed had to interface with the pharmacy system where the medication product is reviewed, released and inventoried. This was no easy feat and took approximately 18 months including rigorous testing of interfaces. With testing complete, UHN piloted the solution for the first time in February 2003. The results of the pilot were mixed: the system design was usable, but the system performance was slow. In other words, while clinicians (physicians, nurses and pharmacists) were willing to use the system for electronic medication management, the system's speed and reliability could not support the clinical practice.

In June 2004, after additional technical work, increased consultation with clinicians, much improved system performance and more testing, on-line medication $\mathrm{CPOE}$ went live for all patients admitted to the General Internal Medicine units at the Toronto General Hospital. This was shortly followed by the implementation of the electronic Medication Administration Record (MAR). Roll-out of the complete EMM system has continued, and the schedule of implementation is shown in Figure 3.

\section{The EfFECt of CPOE AND EMM ON DAY-TO- DAY ACTIVITIES \\ Imagine that one day medication orders are written on paper and the next day, all clinicians need to access the computer system}


Figure 1. Workflow Prior to Implementation

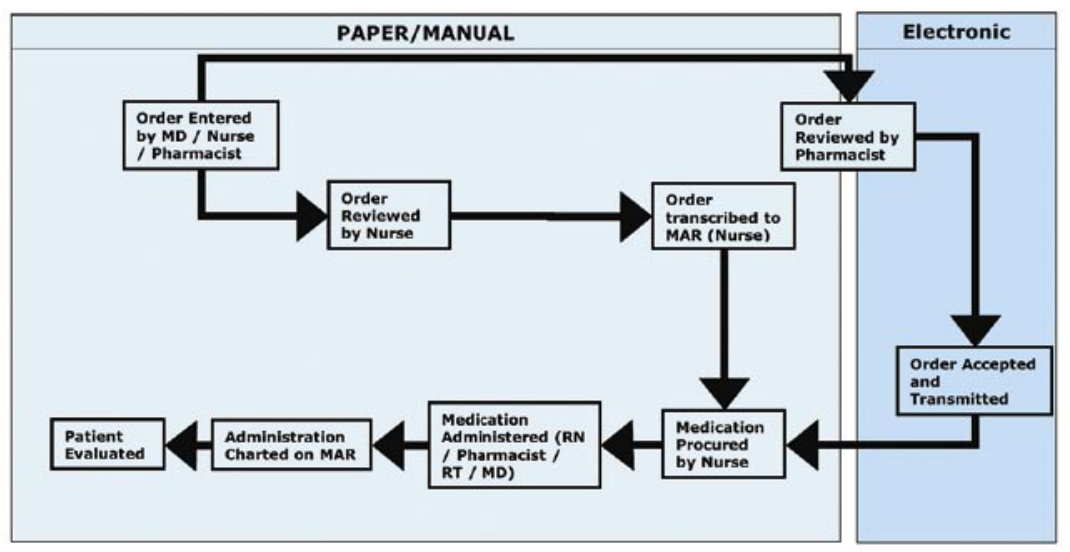

Figure 2. Workflow Post-Implementation

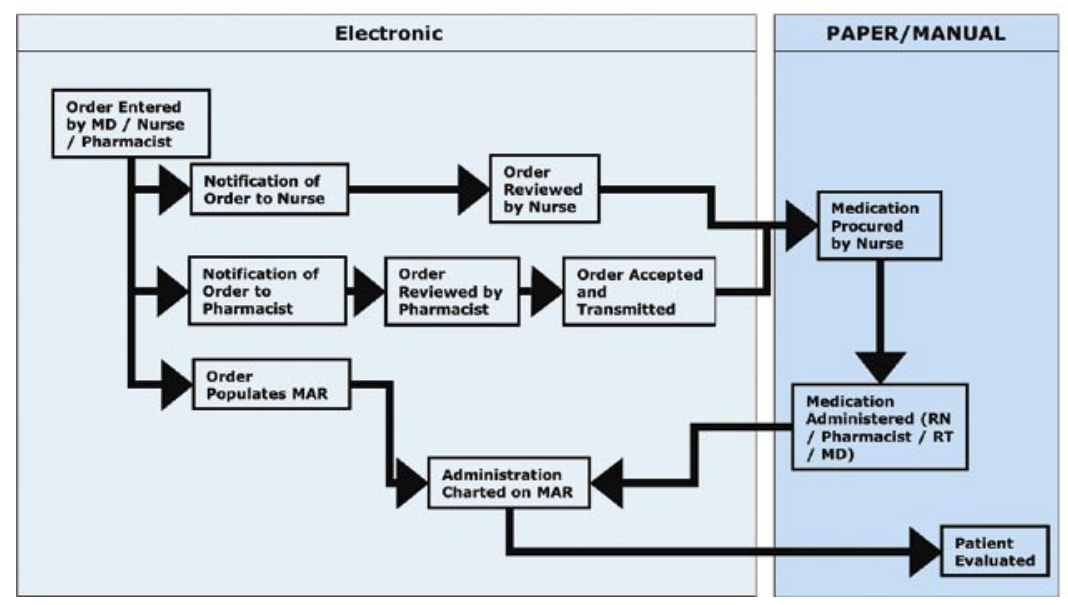

1. Medication orders are entered electronically. Paper orders are no longer processed.

2. Medication information is available online in one location in the electronic chart. Clinicians need only look at the medication history tab in the patient's electronic chart to review the patient's current medications. They will no longer need to find the paper chart or review the numerous pieces of paper making up the patient's medication history. Duplicate order alerts are automatic as are drug/allergy alerts.

3. Medication administration information is located in the electronic MAR and can be accessed from any computer in the hospital. Finding the paper MAR, which is often with the nurse administering the medication, in the medication room or with the pharmacist, is no longer required.

4. Physicians are checking their electronic inbox to review all results. All action items are located in one area of the electronic chart, eliminating the chances of a paper result being missed.

5. Attending physicians can review all orders placed by their team. This provides rapid and complete information on their patient and an improved ability to supervise patient care.

6. Physicians can access the patient's electronic chart from any location in the hospital and from home. The number of verbal or telephone orders is reduced, and the physician can review the patient's electronic chart prior to placing the order.

7. Medical student orders are entered directly for any action related to medication management. Placing orders, reviewing orders and administering the medication are activities that cannot be done without accessing the computer. In addition, the system will not process the on-line medication order until all elements of the order have been entered (e.g., dose, route, etc.). And, a review of the patient's medications may need to take place in order to respond to a drug/allergy alert. In short, transforming the paper medication process into an electronic process is very complex and affects the workflow of all clinicians on the unit.

Although there are too many changes to describe here, reviewing a sample of activities is helpful in getting an appreciation of the changes a clinician will experience with the implementation. into the system and held until a physician reviews the order and electronically co-signs the order. Teaching occurs at the point of computer access and less via review of the written order.

8. Nursing staff check the electronic order notification board and/or their electronic inbox for new medication orders. Information about the medication is stored in the electronic inbox and needs to be reviewed by the nursing staff before administration.

9. Pharmacy staff no longer enters the physician's medication orders into the pharmacy system. Medication orders are automatically interfaced to the Pharmacy system, and the pharmacists review the electronic medication orders.

10. Patients receive their medications more rapidly. The turnaround time between medication order entry and the delivery of the medication to the patient has been reduced. 
11. Reports are available to nurse managers that indicate the "missed doses" by shift. A nurse manager can review the reports before end of shift and follow-up with nursing staff before the shift change.

12. When a review or audit is required, information in the electronic chart can be easily reviewed or reported.

\section{The Human Reaction}

With the introduction of EMM, business is not as usual. Human resistance to change and disruption of the status quo prompted the following types of reactions.

- We don't mind labs and radiology order entry, but don't mess with medication order entry!

- What's wrong with the way we do things today?

- Do I still need to tell the nurse?

- There is nowhere to hide.

We don't mind labs and radiology order entry, but don't mess with medication order entry!

In contrast to orders such as labs and radiology, there is a far greater sensitivity to medication ordering. First, the implication of ordering medications incorrectly is likely to be more serious than ordering the wrong lab test. Second, writing medication orders and personally signing them has been the medical tradition and represents a very personal act. Entering medication orders electronically may not initially reproduce that same sense of control and personal relationship with the patient. As a result of this, the addition of medications to the on-line menu is often received with trepidation, hesitation and concern.
Figure 3. Schedule of Implementation

\begin{tabular}{|c|c|c|}
\hline Group & Services & $\begin{array}{l}\text { Go-Live } \\
\text { Date }\end{array}$ \\
\hline 1 & $\begin{array}{l}\text { General Internal Medicine, Gastrointestinal, } \\
\text { Nephrology \& Emergency }\end{array}$ & $100 \%$ \\
\hline 2 & $\begin{array}{l}\text { Psychiatry (TGH) \& Emergency Psychiatric } \\
\text { Assessment (TWH) }\end{array}$ & $100 \%$ \\
\hline 3 & $\begin{array}{l}\text { TWH General Internal Medicine, Family } \\
\text { Medicine, Cardiology \& Emergency }\end{array}$ & $100 \%$ \\
\hline 4 & $\begin{array}{l}\text { Orthopedics, Rheumatology, General } \\
\text { Surgery, Post-Anesthetic Care Unit (PACU), } \\
\text { Pre-Admission }\end{array}$ & $100 \%$ \\
\hline 5 & $\begin{array}{l}\text { TWH Neurology, Neurosurgery, Step-Down } \\
\text { Unit, Interventional Radiolog }\end{array}$ & $\begin{array}{l}\text { September } \\
2005\end{array}$ \\
\hline 6 & $\begin{array}{l}\text { TGH Cardiovascular Surgery, Cardiac Short } \\
\text { Stay, Cardiology, CICU, Cardiovascular Pre- } \\
\text { Admit, Cath Lab }\end{array}$ & $\begin{array}{l}\text { September } \\
2005\end{array}$ \\
\hline 7 & $\begin{array}{l}\text { PMH - Clinics: Head \& Neck, Breast, BMT, } \\
\text { Gyn-Onc, G.I, Sarcoma Thoracic, Brain, GU }\end{array}$ & $\begin{array}{l}\text { September } \\
2005\end{array}$ \\
\hline 8 & $\begin{array}{l}\text { TGH General Surgery, PACU, Gynecology } \\
\text { Oncology, Urology, ENT/Plastics/Head \& } \\
\text { Neck, Thoracic/Respiratory }\end{array}$ & $\begin{array}{l}\text { November } \\
2005\end{array}$ \\
\hline 9 & TGH Transplant & $\begin{array}{l}\text { January } \\
2006\end{array}$ \\
\hline 10 & TGH \& TWH Intensive Care Units & $\begin{array}{l}\text { March } \\
2006\end{array}$ \\
\hline 11 & PMH Inpatient Units & TBD \\
\hline 12 & $\begin{array}{l}\text { Other Areas: Infectious Disease, Endocrine, } \\
\text { Palliative Care, etc. }\end{array}$ & TBD \\
\hline
\end{tabular}

What's wrong with the way we do things today?

Because medication errors are so difficult to identify in the paper environment, there is a sense that the current system isn't so bad. This mood is described well by Dr. Matthew Morgan in his paper, "In Pursuit of a Safe Canadian Healthcare System: What we do not look for, we will not see. What we do not measure, we will not investigate. What is perceived as unbroken, we will not fix" (2004). Unfortunately, recent studies have shown that adverse events from medical error are unacceptably high, and that the majority of these preventable events are due to medication error (Kohn et al. 1999).

\section{Do I still need to tell the nurse?}

Interestingly, the introduction of an electronic system can change the patterns of verbal communication. Initially, as clinicians get accustomed to the type and amount of information that is stored in the electronic chart, important verbal communication decreases due to the belief that the system has a mechanism for replacing that communication. Clinicians have to be reminded that verbal communication within the healthcare team remains just as important as it was prior to CPOE. In fact, during the implementation phase, communication needs to increase as clinical groups adapt to the new system.

\section{There is nowhere to hide.}

On-line information is far more powerful than information on disparate pieces of paper located around a unit. With the "flick" of a switch, information is collected in the electronic chart, presented and reported differently. This results in workflow and practice issues becoming more transparent.

This level of transparency is uncomfortable. It will result in the perception that an increase in errors has occurred. Whereas in the past, reporting or auditing errors was a cumbersome and lengthy process, electronic information is easier to review, report and present. Errors that have existed in the paper environment, possibly buried within the many layers of the patient's paper record, now appear to be more visible. Additionally, while 
different workflows are tolerated in a paper environment, an electronic environment forces process review and adoption of a best practice standard.

\section{The UneXPeCted Benefits AND INCREASED Patient SAFETY}

While the human factor will affect the implementation of EMM, overcoming these factors yields some unexpected benefits that go beyond medication error reduction, but that, nevertheless, yield increased patient safety benefits.

\section{Better Understanding of Overall Workflow}

Although there have been many advances in the area of medication therapy, there has been very little change in its method of delivery. The same workflow has been adhered to for many years. The introduction of EMM will force a review of the process as clinicians and informaticians work together to marry technology and workflow. This review results in the quick identification of ambiguous or inefficient workflow. EMM cannot support disparate workflows, and this results in the clarification and development of standards and possibly the introduction of new practice and policies.

At UHN, EMM implementation has forced a review of the verbal order policy, the hemodialysis workflow, the consultant order process and policy, and the allergy documentation process and policy.

\section{Increased Communication}

Implementing EMM must be done with all clinical disciplines at the table. While we expect that interdisciplinary communication occurs on a regular basis, in reality, the extremely busy pace of healthcare practice has limited this interchange. As EMM is implemented, the changes to workflow and process must be discussed by an interdisciplinary team. At UHN, this increased interaction between disciplines reinforces informal networks and encourages a better understanding of how the organization functions, resulting in a stronger healthcare team better able to rapidly troubleshoot issues.

\section{Teambuilding}

While teambuilding within the unit is a by-product of this implementation, teambuilding outside the walls of the unit is also a benefit. At UHN, each go-live requires the attention and dedication of many players. The information technology (IT) department works very closely with clinicians' pre- and post- golive ensuring the system meets the practice and workflow needs of the clinicians. This intense collaboration puts the IT professional on the front line of patient care, literally side-by-side with the clinicians. There is a sharing of perspectives and an increase in mutual respect and understanding. IT is no longer seen as a remote department that interferes with patient care by forcing clinicians to change the way they've always done things. They are part of the healthcare team who need clinician feedback and involvement in order to provide the best electronic environment for clinicians to do their work.

Hospital administration and clinical leadership, via the use of a report card and meetings with the unit, also monitor carefully the rate of adoption and productivity of the units. Because the medication management process is so critical to the patient as well as to the overall workings of the organization, these many stakeholders work quickly and closely together to ensure the smoothest transition as possible to EMM.

\section{Implementing EMM must be done with all clinical disciplines at the table.}

\section{Introduction of New Process and Structure for Issue Resolution}

The speed at which issues need to be resolved, as well as their interdisciplinary nature, forces the development of a process and structure for issue resolution. While there are many formal and informal structures already existing in the hospital for issue resolution, it was found that they were unable to make timely decisions that represented the interdisciplinary nature of medication management. As a result, a leadership team with multidisciplinary representation was created for each unit. This team is accessible and able to make rapid and daily decisions that enable the unit to operate as seamlessly as possible. When the issue at hand will affect practice, policies and standards, this team takes the issues to the Electronic Health Record Clinical Advisory Committee and possibly to other committees.

\section{Management and Leadership Engagement}

While UHN has undergone many system implementations, EMM has been one of the longest and most difficult. The sensitivity around medication management and the attention around medication errors and adverse events have made adoption of EMM a closely scrutinized process. While this level of attention can be difficult to manage, it does offer the benefit of engaging administrators, managers and clinical leaders. This engagement means that issues such as practice, standards and policy changes are monitored and addressed promptly. 


\section{CONCLUSION}

Many of the benefits listed in this paper are the subtle and unexpected by-products of CPOE and EMM implementation. Formal and informal interdisciplinary networks are strengthened, improving the functioning of a complex institution. Role and process clarification occurs, allowing the creation of best practices throughout the hospital. Previously hidden errors are brought to light. These unexpected benefits, primarily a result of human factors, provide important additional benefits to a CPOE and EMM implementation. These benefits go beyond medication error reduction and equally improve patient care.

\section{About the Authors}

Howard Abrams is the Director of the Medical Consultation Service, University Health Network (UHN) and Mount Sinai Hospital, and Director of the General Internal Medicine Clinical Teaching Units, Toronto General Hospital. He has lectured internationally in the fields of Clinical Epidemiology, Evidenced Based Medicine, and delivering information at the point-of-care.

Dafna Carr is a Project Director with the Shared Information Management Services (SIMS) at UHN.

Corresponding Author: Dafna Carr, dafna.carr@uhn.on.ca.

\section{References}

Morgan, M.W. 2004. "In Pursuit of a Safe Canadian Healthcare System.” Healthcare Papers 5(3): 10-26.

Kohn, L.T., J.M. Corrigan and M.S. Donaldson, eds. 1999. To Err Is Human: Building a Safer Health System. IOM Committee on Quality of Health Care in America. Washington, DC: National Academy Press.

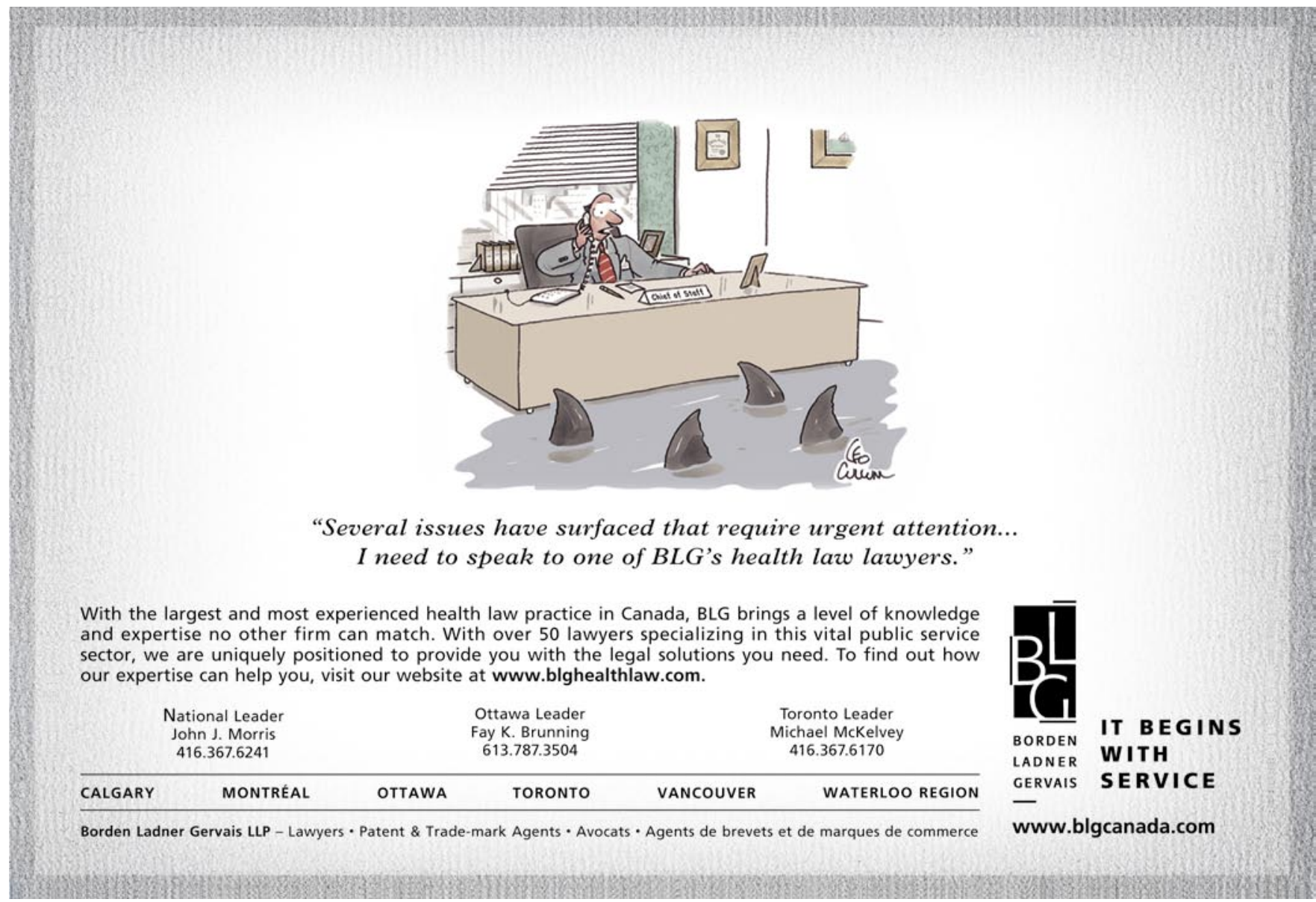

